

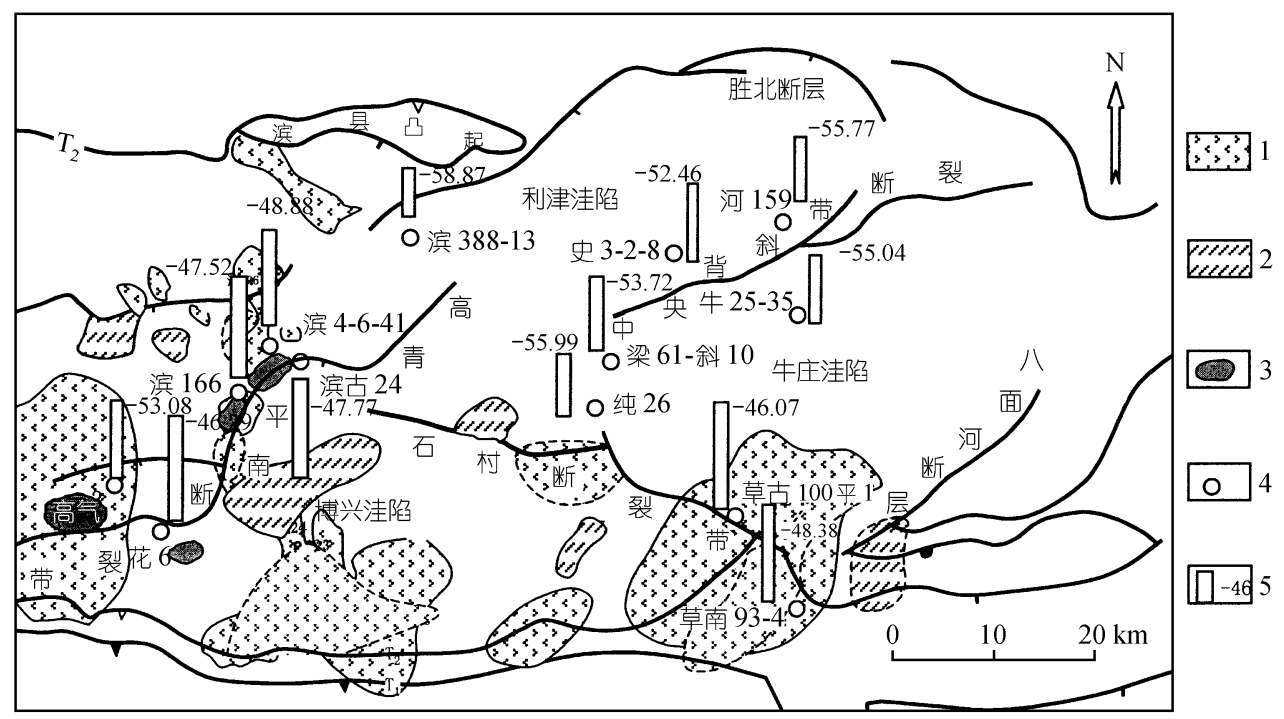

图 1 东营凹陷第三系基性火成岩、二氧化碳气藏天然气 $\delta^{13} \mathrm{C}_{\mathrm{CH}_{4}}$ 值分布 1. 玄武岩; 2. 辉绿岩; 3. $\mathrm{CO}_{2}$ 气藏; 4. 取样井; 5. $\delta^{13} \mathrm{C}_{\mathrm{CH}_{4}}$ 值 表 1 东营凹陷天然气化学成分与碳同位素组成

\begin{tabular}{|c|c|c|c|c|c|c|c|c|c|c|c|c|}
\hline \multirow{2}{*}{ 构造位置 } & \multirow{2}{*}{ 井号 } & \multirow{2}{*}{ 层位 } & \multirow{2}{*}{ 井深/m } & \multicolumn{5}{|c|}{ 化学组分 $/ \%$ (摩尔分数) } & \multicolumn{4}{|c|}{$\delta^{13} \mathrm{C} / \%$ (PDB) } \\
\hline & & & & $\mathrm{CO}_{2}$ & $\mathrm{CH}_{4}$ & $\mathrm{C}_{2} \mathrm{H}_{6}$ & $\mathrm{C}_{3} \mathrm{H}_{8}$ & $\mathrm{C}_{4} \mathrm{H}_{10}$ & $\mathrm{CO}_{2}$ & $\mathrm{CH}_{4}$ & $\mathrm{C}_{2} \mathrm{H}_{6}$ & $\mathrm{C}_{3} \mathrm{H}_{8}$ \\
\hline \multirow{5}{*}{$\begin{array}{c}\text { 高青-平南 } \\
\text { 断裂带 }\end{array}$} & 滨 166 & $\mathrm{O}$ & $2425 \sim 2455$ & 25.41 & 39.49 & 8.19 & 8.52 & \multirow{5}{*}{0.092} & -9.86 & -47.52 & -31.44 & -28.45 \\
\hline & 滨古 24 & $\mathrm{O}$ & $2404 \sim 2410$ & 97.73 & 1.33 & 0.28 & 0.30 & & -6.24 & -47.77 & -28.80 & -28.83 \\
\hline & 滨 4-6-41 & $\mathrm{Es}_{4}$ & $1535 \sim 1569$ & 43.80 & 52.95 & 1.16 & 0.38 & & -9.34 & -48.88 & -33.99 & -27.08 \\
\hline & 花 6 & $\mathrm{Ng}$ & $771 \sim 820$ & 0.056 & 97.21 & 0.49 & 0.044 & & -21.49 & -46.29 & -30.01 & \\
\hline & 高气 3 & $\mathrm{Ng}$ & $833 \sim 850$ & 99.42 & 0.012 & 0.036 & & & -4.29 & -53.08 & -35.98 & -29.59 \\
\hline 利津洼陷 & 滨 338-13 & $\mathrm{Es}_{3}$ & $1735 \sim 1738$ & 1.13 & 95.15 & 0.31 & 0.36 & & & -58.87 & & \\
\hline \multirow[t]{2}{*}{ 南斜坡 } & 草古 100-平 1 & $\mathrm{O}$ & $863 \sim 1010$ & 1.45 & 97.83 & 0.059 & 0.035 & & $\begin{array}{l}-2.74 \\
-2.72\end{array}$ & -46.07 & \multirow{2}{*}{\multicolumn{2}{|c|}{-36.24}} \\
\hline & 草南 93-4 & $\mathrm{O}$ & $900 \sim 907$ & 1.44 & 97.79 & 0.074 & 0.051 & & -15.72 & -48.38 & & \\
\hline 中央 & 史 3-2-8 & $\mathrm{Es}_{3}{ }^{\text {中 }}$ & $3307 \sim 3328$ & 5.20 & 77.49 & 7.78 & 9.05 & & -10.66 & -52.46 & -33.18 & -28.59 \\
\hline \multirow[t]{2}{*}{ 背斜带 } & 河 159 & $\mathrm{Es}_{3}$ & $2946 \sim 2966$ & 4.16 & 80.70 & 4.38 & 6.63 & 2.59 & -14.32 & -55.77 & -33.25 & -28.96 \\
\hline & 牛 $25-35$ & $\mathrm{Es}_{3}{ }^{\text {中 }}$ & $3256 \sim 3271$ & 4.84 & 82.45 & 4.87 & 4.90 & 1.75 & -8.51 & -55.04 & -34.76 & -29.53 \\
\hline \multirow[t]{2}{*}{ 牛庄洼陷 } & 梁 61-斜 10 & $\mathrm{Es}_{3}{ }^{\text {中 }}$ & $3281 \sim 3341$ & 7.43 & 70.26 & 8.17 & 9.67 & 3.35 & -7.54 & -53.72 & -33.72 & -29.44 \\
\hline & 纯 26-21 & $\mathrm{Es}_{4}{ }^{\mathrm{F}}$ & $2600 \sim 2604$ & 1.98 & 78.13 & 5.49 & 8.14 & 3.27 & -17.89 & -55.99 & -35.33 & -29.42 \\
\hline \multirow{2}{*}{\multicolumn{9}{|c|}{$\begin{array}{c}\text { 碳同位素最大值与最小值之差 } \\
\text { 碳同位素标准偏差 }\end{array}$}} & 18.77 & 12.8 & 7.44 & 2.51 \\
\hline & & & & & & & & & 5.82 & 4.25 & 2.39 & 0.79 \\
\hline
\end{tabular}

的含量较低, 碳同位素数据极其不全, 没有在表 1 中列出.

\section{3 结果分析与讨论}

表 1 中, 天然气化学成分以烃类气体和 $\mathrm{CO}_{2}$ 为 主, 本文将主要围绕这两个方面进行讨论. 东营凹陷 $\mathrm{CO}_{2}$ 含量高达 $99.42 \%$, 与印度洋 Reunion 岛富 $\mathrm{CO}_{2}$ 幔源温泉极为相近(99.73\% $)^{[9]}$. 东营凹陷及其邻区基 性火山岩流体包裹体成分研究表明该区基性岩浆活
动本身就携带着大量的幔源 $\mathrm{CO}_{2}{ }^{1)}$. 一些学者 ${ }^{[8,10 ~ 12] ~}$ 将地幔流体总体上分为两大类型：超深流体和上地 幔软流层流体. 后者是以 $\mathrm{H}_{2} \mathrm{O}+\mathrm{CO}_{2}$ 为主的流体, 本 文称为幔源富 $\mathrm{CO}_{2}$ 流体.

图 2 中, 高青-平南断裂带 $\mathrm{CO}_{2}$ 含量近乎 $100 \%$ 的 样品具有幔源特征，与前人的成果 ${ }^{[7]}$ 相吻合. 在高青平南断裂带, $R / R_{\mathrm{a}}$ 值为 $2.54 \sim 3.19^{[7]}$, 具有明显的幔 源氦特征. 随着 $\mathrm{CO}_{2}$ 含量的降低, 样品呈现出有机成 


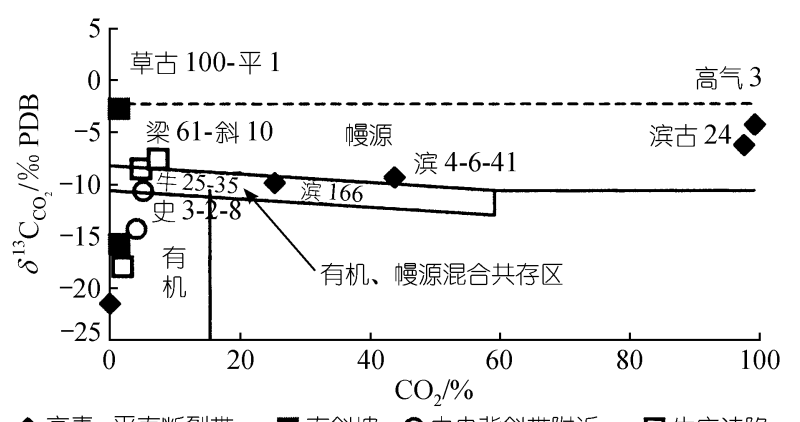

、高青 -平南断裂带

南斜坡 $\mathrm{O}$ 中央背斜带附近

口牛庄洼陷

图 2 东营凹陷 $\delta^{13} \mathrm{C}_{\mathrm{CO}_{2}}-\mathrm{CO}_{2}$ 图

据文献 $[7,13]$, 图中标出了与幔源富 $\mathrm{CO}_{2}$ 流体有关的井号

因和幔源 $\mathrm{CO}_{2}$ 混合特征. 混合作用可能改变了甲烷 碳同位素的组成, $\delta^{13} \mathrm{C}_{\mathrm{CH}_{4}}$ 值在高青-平南断裂带和石 村断裂带普遍升高, 这两个断裂带又是幔源富 $\mathrm{CO}_{2}$ 流体和基性火成岩集中活动的地区(图 1), 两者在空 间分布上存在着密切的相关性. 东营凹陷甲烷碳同 位素的数据结构也存在着高、低两个次总体(图 3), 有 可能是两种不同成因类型的反映. 高 $\delta^{13} \mathrm{C}_{\mathrm{CH}_{4}}$ 值次总 体都分布在高青-平南断裂带和石村断裂带. $\delta^{13} \mathrm{C}_{\mathrm{CH}_{4}}$ 值与 $\mathrm{CO}_{2}$ 含量的关系表明 (图 3), 大多数样品的 $\delta^{13} \mathrm{C}_{\mathrm{CH}_{4}}$ 值与 $\log \mathrm{CO}_{2}$ 值成正比; $\mathrm{CO}_{2}$ 含量大于 $20 \%$ 的 天然气除高气 3 井外, 均属于高 $\delta^{13} \mathrm{C}_{\mathrm{CH}_{4}}$ 值次总体. 有 机成因 $\mathrm{CO}_{2}$ 与有机成因烷烃存在着一定的共生关系, 同样地, 幔源 $\mathrm{CO}_{2}$ 与幔源烷烃之间存在着共生关系. 幔源富 $\mathrm{CO}_{2}$ 流体可能与有机成因油气发生了混合作 用, 形成复合成因烷烃, 包括有机成因烷烃、幔源无机 成因烷烃以及幔源 $\mathrm{CO}_{2}$ 发生还原反应而形成的烷烃.

首先, 在高青-平南断裂带发现了具有幔源特征 的方解石脉, 其 $\delta^{13} \mathrm{C}_{\mathrm{CaCO}_{3}}$ 为-7.9 -7.3\%o(PDB), $\delta^{18} \mathrm{O}$ 值 $\mathrm{CaCO}_{3}$ 为 $10.7 \%$ 13.1\% ( $\left.\mathrm{SMOW}\right)^{1)}$. 对这些方解石 脉气液包裹体作 Raman 光谱分析, 气相中 $\mathrm{CO}_{2}$ 占检 出组分的 $19.6 \%(\mathrm{~mol}), \mathrm{CH}_{4}$ 为 $9.0 \% \sim 14.2 \%(\mathrm{~mol})$; 液 相中 $\mathrm{CO}_{2}$ 为 $0.13 \%(\mathrm{~mol}), \mathrm{CH}_{4}$ 为 $0.08 \%(\mathrm{~mol}), \mathrm{CO}_{3}^{2-}$ 为 $0.4 \mathrm{~mol} / \mathrm{L}$, 其他阴离子在检出限以下. 表明东营凹陷 幔源富 $\mathrm{CO}_{2}$ 流体含有一定数量的富 ${ }^{13} \mathrm{C}$ 的幔源甲烷. 赫英等人 ${ }^{[14]}$ 分析了东营凹陷及其邻区火成岩的气液 包裹体成分, 其中新生代碱性橄榄玄武岩富含 $\mathrm{CO}_{2}$, 在包裹体气相检出组分中的含量为 $47.9 \% \sim 72.7 \%$,
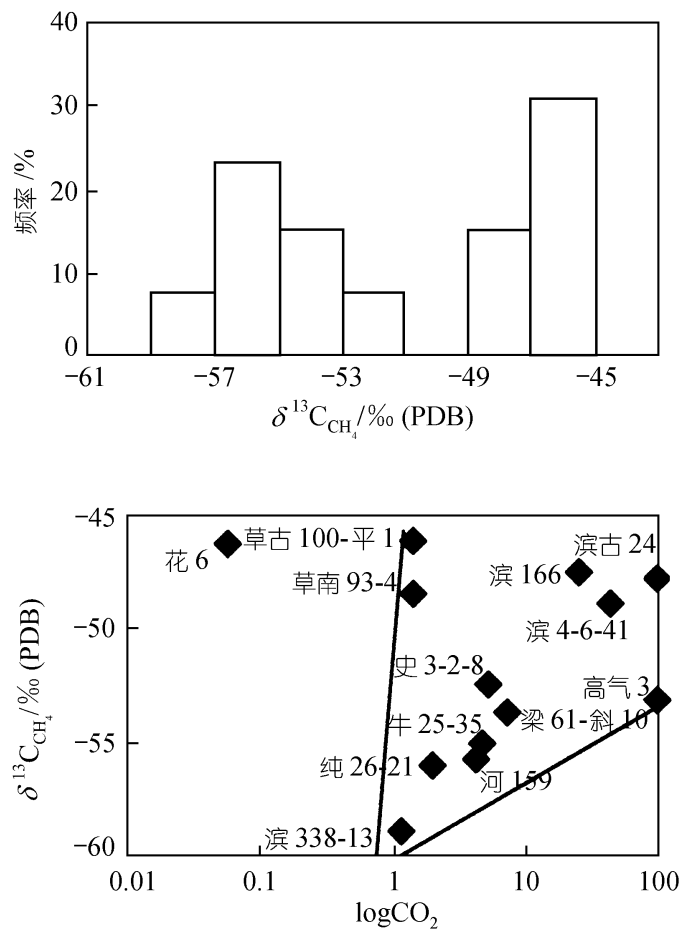

图 3 东营凹陷天然气甲烷碳同位素数据结构及其与 $\mathrm{CO}_{2}$ 含量的关系

其碳同位素也具有典型的地幔特征。在这些包裹体 的气相成分中, $\mathrm{CH}_{4}$ 的含量为 $3.8 \% \sim 28.2 \%$, 是本区 幔源富 $\mathrm{CO}_{2}$ 流体含有幔源甲烷的一个旁证.

其次, 表 1 中 $\delta^{13} \mathrm{C}_{\mathrm{CH}_{4}}$ 值均小于-30\%o, 如果从数 值上直接判识, 均具有机成因特征 ${ }^{[5]}$. 在通常情况下, 天然气甲烷碳同位素组成的变化被认为是由生烃母 质的类型及其热演化、盆地流体-岩石相互作用(如 TSR 和 BSR)引起的. 东营凹陷主要发育沙四上亚段 和沙三段两套生烃岩系 ${ }^{2)}$, 其中沙四上亚段主要为腐 泥型干酪根 $(96 \%)$, 沙三段为含腐植腐泥型-腐植腐 泥型干酪根, 总的来说沙四上亚段的热演化程度高 于沙三段. 根据天然气甲烷碳同位素组成随生烃母 质类型和热演化程度而变化的规律 ${ }^{[15]}$, 东营凹陷有 机质类型和热演化程度对于甲烷碳同位素组成的变 化而言起到了相互抵消的作用. 热演化程度造成天 然气甲烷碳同位素组成变化的另一个判据是 $\mathrm{C}_{2} / \mathrm{C}_{1}$ 与 $\delta^{13} \mathrm{C}_{\mathrm{CH}_{4}}$ 值的负相关关系 ${ }^{[16]}$, 在东营凹陷并不存在这

1) 金之钧, 刘树根, 曾溅辉, 等. 973 项目 09 课题中国典型叠合盆地深部流体与盆地流体相互作用及成藏效应中期工作进展报告. 2001

2) 张林晔, 孔祥兴, 李政, 等. 有效烃源岩地球化学研究, 胜利探区油气资源评价. 2000 
种关系(表 1). 高青-平南断裂带的有机成因油气来自 博兴洼陷的沙四上亚段和沙三段烃源岩. 尽管纯 26-21 和梁 61-斜 10 在构造上划归为牛庄洼陷, 但是 其有机成因油气同样源自博兴洼陷的沙四上亚段和 沙三段烃源岩. 高青-平南断裂带的油气埋藏浅(表 1), 埋藏热演化程度低, 但是其 $\delta^{13} \mathrm{C}_{\mathrm{CH}_{4}}$ 值却高于纯 26-21 和梁 61-斜 10 . 所以, $\delta^{13} \mathrm{C}_{\mathrm{CH}_{4}}$ 值在高青-平南断裂带的 升高不应是盆地自身演化的结果, 可能与幔源流体 的注人有关(图 1). 南斜坡天然气样品采自乐安油田, 烃源岩为沙四上亚段未熟-低熟腐泥型烃源岩, 从源 岩类型及其热演化程度看, 均不应该出现 $\delta^{13} \mathrm{C}_{\mathrm{CH}_{4}}$ 值升 高的现象. 在南斜坡乐安油田火成岩发育区, $\delta^{13} \mathrm{C}_{\mathrm{CH}_{4}}$ 值升高的原因也可能是幔源流体的作用. 在热 $(80 \sim$ $100<T<150 \sim 200^{\circ} \mathrm{C}$ ) 的作用下, 烃类在水的参与下 会与硫酸盐矿物发生反应(TSR), 生成蚀变的烃类, 碳酸盐矿物, $\mathrm{CO}_{2}, \mathrm{H}_{2} \mathrm{~S}, \mathrm{~S}$ 以及金属硫化物等, 并产生 一定的热 ${ }^{[17]}$. TSR 反应的动力学效应可使 $\delta^{13} \mathrm{C}_{\mathrm{CH}_{4}}$ 值 升高, 生成的 $\mathrm{CO}_{2}$ 和碳酸盐矿物的碳同位素值具有 有机成因特征 ${ }^{[17 ~ 20]}$. 东营凹陷 $\delta^{13} \mathrm{C}_{\mathrm{CH}_{4}}>-50 \%$ o(PDB) 者, 只有少数样品的 $\mathrm{CO}_{2}$ 为有机成因(表 1, 图 2). TSR 反应的重要判据是丙烷碳同位素数据的离差大 于乙烷, 更大于甲烷 ${ }^{[18]}$, 而东营凹陷天然气碳同位 素数据的离差却呈现出相反的情况. 细菌硫酸盐还 原反应(BSR)的碳同位素行为与 TSR 十分相似 ${ }^{[17]}$. 上 述分析表明, 生烃母质的类型及其热演化、盆地流体岩石相互作用不应是造成东营凹陷高青-平南断裂带 和石村断裂带天然气 $\delta^{13} \mathrm{C}_{\mathrm{CH}_{4}}$ 值升高的主要原因.

最后, 深部流体上升过程中热能传递的定量研 究表明 ${ }^{1)}$, 幔源富 $\mathrm{CO}_{2}$ 流体是良好的热能载体. 硫酸 盐热还原反应是放热的可逆反应 ${ }^{[17]}$, 温度较高的幔 源 $\mathrm{CO}_{2}$ 的注人必然使这一反应向相反的方向进行, 即还原态的 $\mathrm{S}$ 与 $\mathrm{CO}_{2}$ 反应生成硫酸盐和甲烷. 不仅如 此, 野外观察和室内实验均表明, 在 $250^{\circ} \mathrm{C}$ 的条件下 $\mathrm{CO}_{2}$ 与 $\mathrm{Fe}_{2} \mathrm{SiO}_{4}$ 反应而生成 $\mathrm{CH}_{4}{ }^{[2]}$. 东营凹陷还原态物 质较为丰富, 高温幔源 $\mathrm{CO}_{2}$ 注人盆地之后, 可能会 遭受还原反应生成甲烷, 使天然气 $\delta^{13} \mathrm{C}_{\mathrm{CH}_{4}}$ 值升高. $\mathrm{CO}_{2}$ 被还原为 $\mathrm{CH}_{4}$ 的前提应当是较为还原的环境, 即 幔源 $\mathrm{CO}_{2}$ 的注人量小但能量高. $\mathrm{CO}_{2}$ 被还原成 $\mathrm{CH}_{4}$ 的 作用越强烈, 幔源 $\mathrm{CO}_{2}$ 的消耗也就越多, 因此 $\delta^{13} \mathrm{C}_{\mathrm{CH}_{4}}$ 值与 $\mathrm{CO}_{2}$ 含量会呈现负相关关系. 草南 $100-$ 平 1 的 $\delta^{13} \mathrm{C}_{\mathrm{CH}_{4}}$ 和 $\delta^{13} \mathrm{C}_{\mathrm{CO}_{2}}$ 值(表 1)均有所升高, 可能是
这种反应的结果.

\section{4 结论}

研究表明, 东营凹陷高青-平南断裂带和石村断 裂带是火山活动、岩浆作用和幔源富 $\mathrm{CO}_{2}$ 流体的重 要活动区. 甲烷碳同位素数据分为高 $\delta^{13} \mathrm{C}_{\mathrm{CH}_{4}}$ 值和低 $\delta^{13} \mathrm{C}_{\mathrm{CH}_{4}}$ 值两个次总体, 高 $\delta^{13} \mathrm{C}_{\mathrm{CH}_{4}}$ 值次总体分布在幔 源流体活动强烈的高青-平南断裂带和石村断裂带. 研究认为, 有机质类型、埋藏热演化程度和盆地流体岩石反应不是造成甲烷碳同位素变化的主要原因. $\delta^{13} \mathrm{C}_{\mathrm{CH}_{4}}$ 值升高的主要原因可能是幔源富 $\mathrm{CO}_{2}$ 流体含 有幔源甲烷以及部分幔源 $\mathrm{CO}_{2}$ 可能被还原为甲烷. 这种具有幔源成因的烷烃与有机成因烷烃的混合, 使 $\delta^{13} \mathrm{C}_{\mathrm{CH}_{4}}$ 值总体上具有有机成因的特征. 考虑到东 营凹陷幔源流体活动的复杂性, 尚不能简单地应用 质量平衡方程计算幔源碳的贡献量.

幔源富 $\mathrm{CO}_{2}$ 流体是热能的良好载体, 且在我国 东部含油气裂谷盆地的活动具有一定的普遍性. 这 种研究对于深人探讨油气生成过程中的有机-无机相 互作用具有一定的意义.

致谢胜利油田李不龙、张善文、廖永胜等给予大力支持, 刘惠民、冯有良等提供了大量的地质资料, 作者一并致谢. 本工作受国家重点基础研究发展规划项目(G1999043309) 和中国博士后科学基金资助。

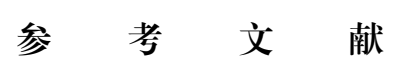

1 Clifton C G, Walters C C, Simoneit B R T. Hydrothermal petroleum from Yellowstone National Park, Wyoming, USA. Applied Geochemistry, 1990, 5: 109 191

2 豪厄尔 D G. 能源气的未来. 杨登维, 李大良, 译. 北京: 石油 工业出版社, 1999. 89 151

3 Price N J. Aspects of gravity tectonics with special reference to the development of listric faults. J Geol Soc London, 1977, 103: $311 \sim 327$

4 Jin Q, Xion S, Lu P. Catalysis and hydrogenation: Volcanic activity and hydrocarbon generation in rift basins, eastern China. Applied Geochemistry, 1999, 14(5): $547 \sim 558$

5 戴金星. 戴金星天然气地质和地球化学论文集. 北京: 石油工 业出版社, 2000. 125～133, 190 227

6 徐永昌. 天然气中的幔源稀有气体. 地学前缘, 1996, 3(3-4): 63 $\sim 71$

7 戴金星, 宋岩, 戴春森, 等. 中国东部无机成因气及其气藏形成 条件. 北京: 科学出版社, $1995.1 \sim 211$

8 郑建平, 路风香. 古地幔流体及其在大陆克拉通地幔演化中的 意义一一以华北地台为例. 地学前缘, 1996, 3(3-4): 187 193

9 Marty B, Meynier V. Geochemistry of gas emanations: A case 
study of the Reunion Hot Spot, Indian Ocean. Applied Geochemistry, 1993, 8: $141 \sim 152$

10 路凤香. 深部地幔及地幔流体. 地学前缘, 1996, 3(3-4)：181 186

11 杜乐天, 王驹. 气体地球动力学一一一个重要的研究方向. 地 球科学进展, 1993, 8(6): 66 73

12 Haggerty S E. Superkimberlites: A geodynamic diamond window to the Earth's core. EPSC, 1994, 122: $57 \sim 69$

13 Lesniak P M, Sakai H, Ishibashi J. Mantle helium signal in the West Carpathians, Poland. Geochemical Journal, 1997, 31(6): 383 $\sim 394$

14 赫英, 王定一, 冯有良, 等. 胜利油田火山岩中的流体包裹体成 分及其意义. 地球化学, 1996, 25(5): 468 473

15 王大锐. 油气稳定同位素地球化学. 北京: 石油工业出版社, 2000. $219 \sim 225$

16 Stahl W J, Carey B D. Source-rock identification by isotope analyses of natural gases from fields in the Val Verde and Delaware basins, west Texas. Chemical Geology, 1975, 16: $257 \sim 267$
17 Machel H G, Krouse H R, Sassen R. Products and distinguishing criteria of bacterial and thermochemical sulfate reduction. Applied Geochemistry, 1995, 10: 373 389

18 Krouse H R, Viau C A, Eliuk L S, et al. Chemical and isotopic evidence of thermochemcial sulfate reduction by light hydrocarbon gases in deep carbonate reservoirs. Nature, 1988, 333: 415 419

19 Dixon G, Davidson G. Stable isotope evidence for thermochemical sulfate reduction in the Dugald River (Australia) strate-bond shale-hosted zinc-lead deposit. Chemical Geology, 1996, 129: 227 246

20 Mountjoy E W, Green D, Machel H G, et al. Devonian matrix dolomites and deep burial carbonate cements: A comparison between the Rimbey-Meadowbrook reef trend and the deep basin of west-central alberta. Bulletin of Canadian Petroleum Geologists, 1999, 47: 487 509

(2002-02-20 收稿, 2002-05-15 收修改稿) 